\section{Melatonin-Milch macht's}

D er Japaner Hajime Kimata hat zahlreiche Zusammenhänge zwischen emotionalem Erleben und allergischen Symptomen aufgedeckt - sei es der negative Einfluss von stressigen Videospielen oder dauerndem Handygeklingel auf das atopische Ekzem, der positive Einfluss von Mozartmusik und Küssen auf allergische Hautreaktionen oder die lindernde Wirkung von Weinen und Schluchzen auf die Symptome einer Naturlatexallergie. Eine aktuelle Publikation beschreibt nun den antiallergischen Effekt des Stillens unmittelbar nach Sehen eines lustigen Films: Bei derart „behandelten“ atopischen und nicht

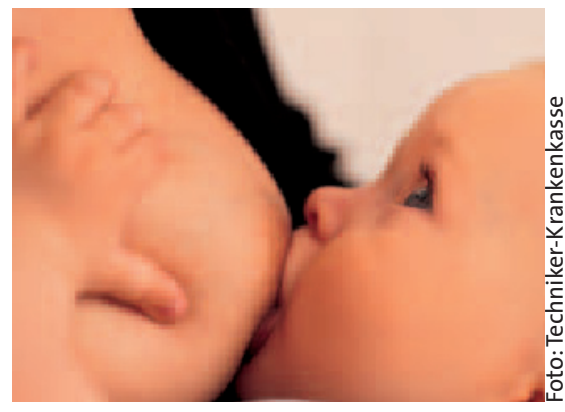

atopischen Müttern stieg die Melatoninkonzentration in der Muttermilch an, die damit gestillten Säuglinge mit atopischem Ekzem reagierten anschließend vermindert im Pricktest. Nach dem Sehen eines neutralen Kontrollfilms blieben diese Veränderungen aus.

bk

Kimata H. J Psychosom Res 2007; 62:

699-702

\title{
Wer zahlt für Alternativverfahren?
}

E in 2003 geborener Junge war über die Eltern privat krankenversichert. Schon als Baby litt er an schwerer atopischer Dermatitis und war allergisch gegen Milcheiweiß. Deshalb ernährten ihn die Eltern mit der Aminosäurenahrung Neocate. Außerdem wurde das Kind akupunktiert.

Die private Krankenversicherung weigerte sich, diese Kosten zu erstatten. Daraufhin klagte der Vater und setzte sich beim Amtsgericht Stuttgart durch. Der Schulmedizin sei keine Therapie bekannt, die Neurodermitis wirklich heilen könne, so der Amtsrichter. Bei dem Kind habe man es mit allen gängigen Behand- lungen versucht, ohne die Beschwerden bessern zu können. Angesichts dieser Situation sei die Akupunktur medizinisch notwendig, weil sie den Juckreiz lindere. Auch die Kosten für Neocate müsse die Krankenversicherung erstatten, obwohl sie es als Nahrungsmittel einstufe. Wenn Blutuntersuchungen die Unverträglichkeit von Milcheiweiß zeigten, sei es nicht möglich, auf gängigen Ersatz für die Flaschennahrung auszuweichen. Unter diesen Umständen sei Aminosäurenahrung als Arzneimittel anzusehen. Ein Urteil für eine abendfüllende Diskussion! gri

Amtsgericht Stuttgart, 16 C 4823/05

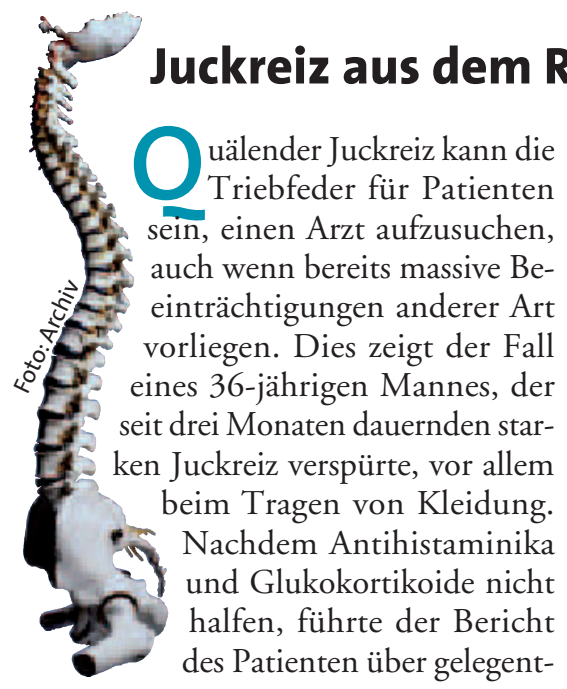

\section{ückenmark}

liche Nackensteifigkeit und Kopfschmerzen auf die richtige Fährte: Die neurologische Untersuchung ergab Auffälligkeiten an den oberen Extremitäten mit Hypoästhesie, Parästhesie und Muskelschwäche, das MRT eine Veränderung vom ersten bis zum siebten Halswirbel. Der Tumor wurde operativ entfernt, die histologische Untersuchung führte zur Diagnose Ependymom. Der Patient nahm anschließend wieder an Kraft zu und der Juckreiz verschwand. $\quad b k$

Wiesner T et al. Lancet 2007; 370: 290

\section{Nasaler IL-10-Mangel?}

nterleukin-10 wird von zahlreichen

Zelltypen sezerniert und spielt eine wichtige Rolle in der Induktion und Aufrechterhaltung einer immunologischen Toleranz. Möglicherweise trägt IL-10 auch wesentlich dazu bei, dass die Nasenschleimhaut trotz der konstanten Exposition gegenüber Mikroorganismen und anderen Umweltfaktoren kaum immunologische Aktivitäten entfaltet. Eine neue Studie mit gesunden Probanden sowie mit Patienten mit einer Hausstaubmilbenallergie unterstützt diese Hypothese: In beiden Kollektiven ließ sich immunhistochemisch eine IL-10-Expression der nasalen Epithelzellen nachweisen - die mukosalen Epithelzellen der Allergiepatienten produzierten allerdings umso weniger IL-10, je stärker ihre allergischen Symptome waren. Wie der genaue Pathomechanismus einer geringeren IL-10-Synthese bei Allergiepatienten aussieht, ist unklar. Dessen ungeachtet scheint IL-10 ein interessantes Zielmolekül für neue antiallergische Therapieoptionen zu sein.

bk

Muller B et al. Allergy 2007; 62: 1014-22

\section{Präventives}

\section{Bakterium}

ur ein toter Helicobacter
pylori ist ein guter Helicobacter pylori! Diese These mag aus Sicht der Gastroenterologen richtig sein, für die Allergiepräven-

tion ist sie aber grundverkehrt, wie eine retrospektive Datenerhebung zeigt. Umweltmediziner aus New York hatten bei 7.663 Erwachsenen eine Infektion mit dem Magenkeim mit dem Vorliegen von Asthma oder allergischer Rhinits in Beziehung gesetzt. Helicobacter-positive Patienten litten seltener unter Asthma (Odds Ratio 0,79) und unter Heuschnupfen (Odds Ratio 0,77). Die Helicobacter-Infektion scheint also - passend zur Hygiene-Hypothese - das Immunsystem in Richtung Toleranz zu trimmen. red

Chen Y et al. Arch Intern Med 2007; 167: $821-7$ 